\title{
Design of step counting system of multi-function
}

\author{
Biqing $\mathrm{Li}^{1, \mathrm{a}}$, Zhao $\mathrm{Li}^{2, \mathrm{~b}, *}$, Jinfeng Qin 1, a \\ ${ }^{1}$ College of Mechanical and Electronic Engineering, Hezhou University, Hezhou Guangxi 542899, \\ China; \\ ${ }^{2}$ Management Engineering Department, Guangxi vocational and technical college of communications, \\ Nanning Guangxi 545000, China; \\ ajanliful@163.com, b229292710@qq.com
}

\section{Keywords: single chip microcomputer; Step gauge; Wireless communication}

\begin{abstract}
This design is mainly based on single chip as a step counting system control core, the overall system contains two modules: the transmitter end and the receiver. The transmitter comprised of a regulating circuit and a wireless communication module, the receiver can be divided into four small modules, respectively, the wireless communication module, keys module, clock circuit module and display module. Walking distance can be calculated by the size of the stride multiplied by the number and the size of the stride can increase or decrease by a key module implementation. Transmitter using mercury switch as the sensor, the use of mercury switch every tilt to control on-off circuit, implementation steps, steps of virtual circuit instead of walking. After collecting the data through the two wireless modules between serial data transceiver, finally sent to the display screen is displayed. This design is based on single chip design, more intelligent, easy to use, and easy to carry. Then in design for future upgrade maintenance, and add functionality, convenient for later to lay a good foundation.
\end{abstract}

\section{Overall Design}

The designed system is composed of wireless transmitting terminal and receiving terminal. The wireless transmitting terminal mainly comprises voltage stabilizing circuit, sensing part and wireless communication module. The wireless receiving terminal mainly comprises wireless communication module, clock circuit module, key circuit module and LCD display module. Firstly the mercury switch at transmitting terminal substitutes the number of steps, corresponding to the actual number of steps. One pulse is realized when pressing once the key, representing the step number, which is transmitted wirelessly via wireless communication module to be processed at receiving terminal. The LCD module displays the step number, and calculates walking distance according to set step size.

To put it simply, NRF24L01 is just a monolithic wireless transceiver chip manufactured by NORDTC and provided with four work modes of transmitting, receiving, idle and power failure, wherein the latter two work modes consume very low power. $1.9 \mathrm{~V}$ to $3.6 \mathrm{~V}$ voltage is required when chip is transceiving. The current consumption is $11.2 \mathrm{~mA}$ in transmitting and $12.5 \mathrm{~mA}$ in receiving. NRF24L01 has fine performance in performance parameters, small volume, and is compatible with other wireless modules, have power functions of automatic re-transmitting and automatic answering into the bargain. Hence it is popular in a great many application areas, such as: wireless sensor, wireless remote control, thief-proofer, intelligent movement device, etc.

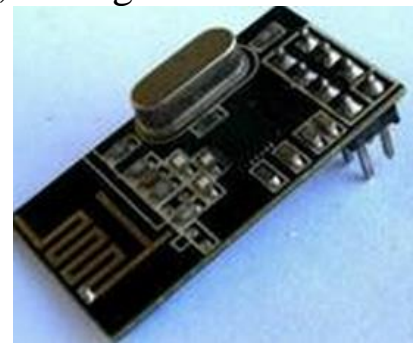

Figure 1 Real object of NRF24L01 


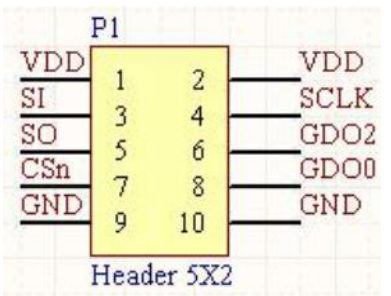

Figure2 Drawing of pin of NRF24L01

\section{Hardware circuit design}

After defining the scheme and elements needed, schematic is drawn with Protel99 software, and be sure to pay close attention to packaging problem in drawing. The package of some elements cannot be found in package library but need to be measured and drawn by oneself. After simulating successfully, draw PCB, and consider the reasonableness of general layout before wiring. The line size should be proper.

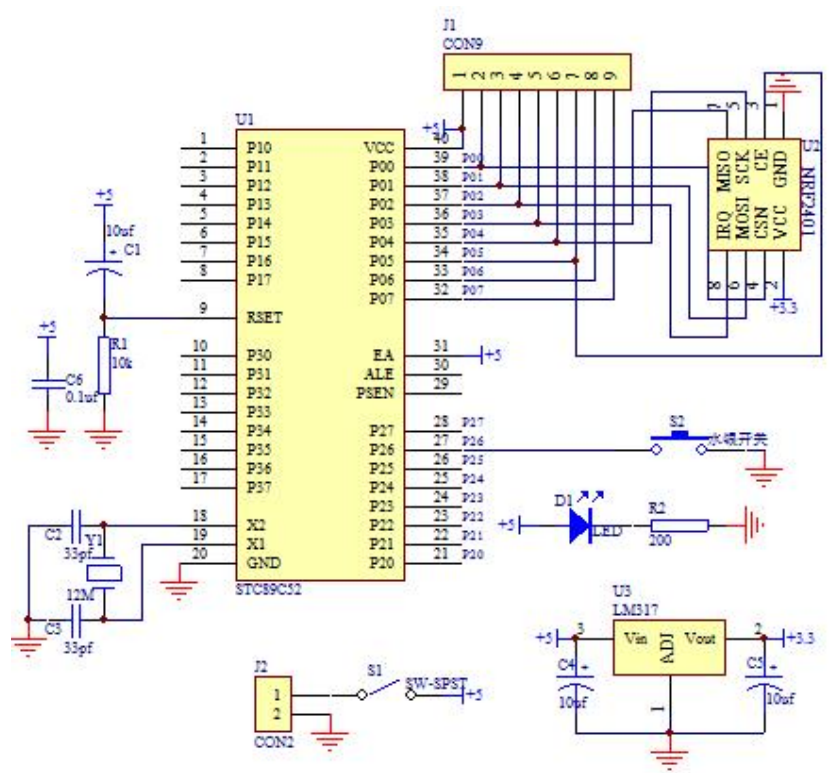

Figure 3 Schematic of transmitting terminal

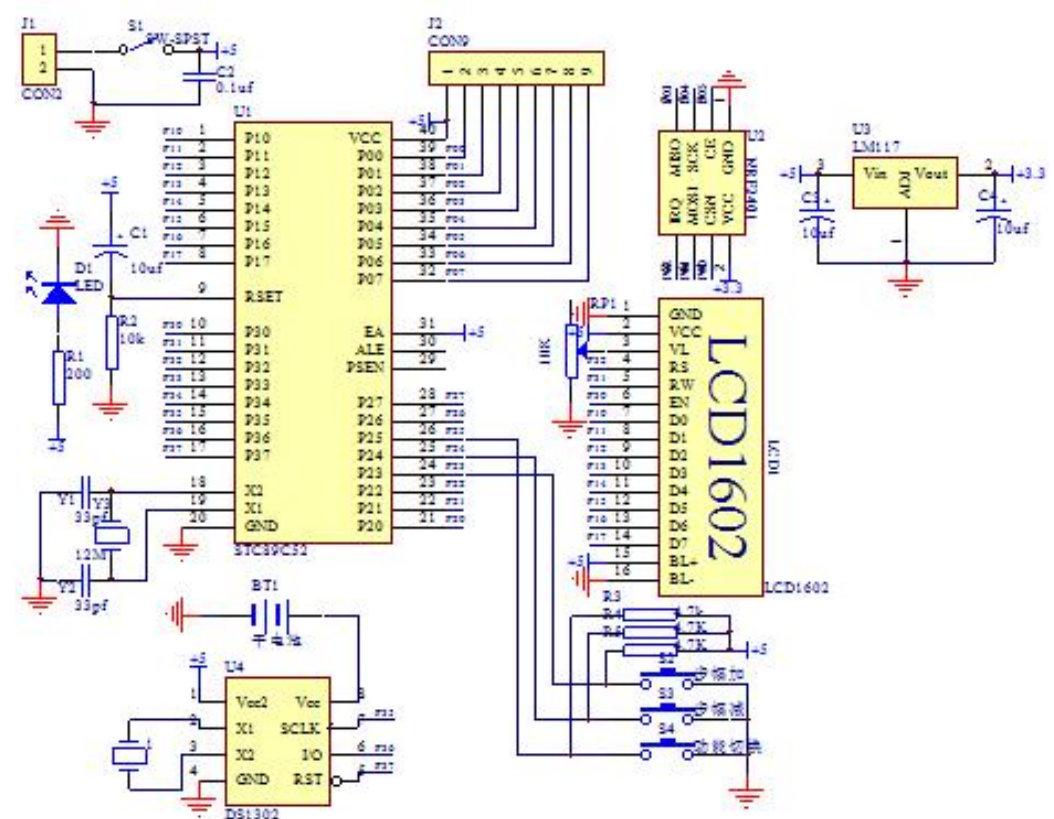

Figure 4 Schematic of receiving terminal 
(1) LCD1602 display circuit

1602LCD liquid crystal display is driven by $5 \mathrm{v}$ voltage, has backlight function and can display two lines with 16 characters for each line. The Chinese characters cannot be displayed. The pins of this display in circuit is as shown in figure 11. The backlight for screen is sometimes burned out when just electrified. To cope, a $1 \mathrm{k}$ resistor can be connected beside pin 15 in series to prevent too high voltage. The brightness of screen can be adjusted via varistor.

(2) Voltage stabilizing circuit

As the wireless module uses voltage of $1.9 \mathrm{~V}$ to $3.6 \mathrm{~V}$, while our power supply is $4.5 \mathrm{~V}$, we need to convert $4.5 \mathrm{~V}$ voltage to be within $3.6 \mathrm{~V}$. Then we can adopt a voltage-stabilizing chip for this purpose.

(3) Wireless module

The design of wireless module functions to connect transmitting terminal and receiving terminal in series. The NRF24L01 belongs to monolithic radio frequency type, a novel type. On chip is configured many devices [6]. NRF consumes extremely low power, with power consumption for receiving slightly lower than that for transmission.

\section{System program design}

The software design for SCM should consider following problems:

(1)Highlight concrete functional requirements of this software design, divide system software design into several small and independent modules, to construct a correct general frame, thereby making programming simple with clear clue.

(2)Form a good programming habit, such as adopting structurization, modularization and subroutinization, etc., which are of great help to later debugging and modification;

(3)Create an accurate mathematical model to improve system performance via simulation software and get the parameters needed by design;

(4)Drawn up diagram for program flow;

(5)Reasonably distribute and utilize system resources;

(6)Add notes to program to facilitate reading by oneself;

(7) Avoid software design being disturbed by too many factors as far as possible to guarantee system reliability.

\section{Debugging and result}

After defining system scheme, I divided the main work into several steps: the first step is to design schematic using Protel99 software, then execute PCB; the second step is to simulate software design system; the third step is to install Keil $\mathrm{C}$ language programming to simulate control of SCM. When nothing is wrong with simulation result, the originally programmed program can be imported to SCM, then power is connected to examine whether the designed work achieves scheduled target.

\section{Summary}

Widely applied in intelligent domains, SCM can facilitate people's life significantly. Thus to master SCM knowledge appears especially important for our students majoring in communication engineering. However, the SCM knowledge is mostly deep and hard to be easily mastered, but needs to be delved into and learned. I believe it is not impossible to become proficient after long-term accumulation, even if we cannot completely apply it with ease.

This work is supported the following fund:2016 The project of improving the basic ability of young teachers in Colleges and universities in Guangxi:"Design and development of electronic commerce platform of agricultural products based on Semantic Technology"(No,KY2016YB455).2015 college students' innovative training program: "Research on the application of value added travel experience in the mobile terminal of the 'ethnic custom travel' in Guangxi" (No 201511838070);\&\& "The design and development HeYuanTong Campus Mobile Phone APP based on Android" (No 
201511838034).Project of scientific research and technology development project of Hezhou: "Design and implementation of agricultural products e-commerce platform based on Semantic Technology" (No,Hekeneng 1506006).

\section{References}

[1] B.Q LI, Y.F LING, H.Y ZHANG, S.Y ZHENG: The Design and Realization of Cherry Tomato Harvesting Robot Based on IOT. International Journal of Online Engineering, 12(12), 23, (2016).

[2] B.Q LI, W.L GUAN, S.Y Zheng, X.G Yue: OPTIMISATION DESIGN OF CORN PRECISION SEEDER BASED ON MULTI-ROUTE AND MULTI-CHANNEL CONTROL. JOURNAL OF THE BALKAN TRIBOLOGICAL ASSOCIATION, 21(4A), 1215, (2015).

[3]S.Y Zheng, et al, Social Work in Teen Addiction Correction Services Research Under the New Situation, in: PROCEEDINGS OF THE 2015 4TH NATIONAL CONFERENCE ON ELECTRICAL, ELECTRONICS AND COMPUTER ENGINEEERING (NCEECE 2015), Xian, China, 2015, PP.252-255.

[4] B.Q Li, et al, Intelligent Control Management System and Its Application, in: PROCEEDINGS OF THE 2016 INTERNATIONAL CONFERENCE ON ECONOMICS AND MANAGEMENT INNOVATIONS, Wuhan, China, 2016, PP.68-71.

[5] B.Q Li, et al, Design and Implementation of Tanks War Game Based on the Android Platform, in: PROCEEDINGS OF THE 2016 2ND WROKSHOP ON ADVANCED RESEARCH AND TECHNOLOGY IN INDUSTRY APPLICATIONS, Dalian, China, 2016, PP.963-966.

[6] B.Q Li, et al, Design of a Tea Garden Antifreezing Control System, in: PROCEEDINGS OF THE 2016 6TH INTERNATIONAL CONFERENCE ON MACHINERY, MATERIALS, ENVIRONMENT, BIOTECHNOLOGY AND COMPUTER (MMEBC), Tianjin, China, 2016, PP. 736-738.

[7] B.Q Li, et al, Design of Electronic Compass, in: PROCEEDINGS OF THE 2016 6TH INTERNATIONAL CONFERENCE ON MACHINERY, MATERIALS, ENVIRONMENT, BIOTECHNOLOGY AND COMPUTER(MMEBC), Tianjin, China, 2016, PP.1240-1243.

[8] B.Q Li, et al, Research of Automatically Light-Adjusting Lamp, in: PROCEEDINGS OF THE 2016 INTERNATIONAL CONFERENCE ON COMPUTER ENGINEERING, INFORMATION SCIENCE \& APPLICATION TECHNOLOGY (ICCIA 2016), Guilin, China, 2016, PP. 249-252.

[9] B.Q Li, et al, The Design and Realization of Fruit Harvesting Robot Based on IOT, in: PROCEEDINGS OF THE 2016 INTERNATIONAL CONFERENCE ON COMPUTER ENGINEERING,INFORMATION SCIENCE \& APPLICATION TECHNOLOGY (ICCIA 2016), Guilin, China, 2016, PP.261-264.

[10] B.Q Li, et al, A New Type of Automatic Opening and Closing Light-Operated Curtain, in: PROCEEDINGS OF THE 2016 INTERNATIONAL CONFERENCE ON MECHATRONICS ENGINEERING AND INFORMATION TECHNOLOGY(ICMEIT), Xian, China, 2016, PP.66-69.

[11] B.Q Li, et al, Design of the Intelligent Air Humidifier, in: PROCEEDINGS OF THE 2016 INTERNATIONAL CONFERENCE ON MECHATRONICS ENGINEERING AND INFORMATION TECHNOLOGY (ICMEIT), Xian, China, 2016, PP.201-203.

[12] B.Q Li, et al, The Design Implementation of the APP of Experiencing Guangxi Folk Custom, in: PROCEEDINGS OF THE 2016 INTERNATIONAL CONFERENCE ON ECONOMICS AND MANAGEMENT INNOVATIONS, Wuhan, China, 2016, PP.47-50.

[13] S.Y Zheng, et al, Digital Display Design of Ethnic Clothing of Nanling, in: PROCEEDINGS OF THE 4TH INTERNATIONAL CONFERENCE ON MECHATRONICS, MATERIALS. CHEMISTRY AND COMPUTER ENGINEERING 2015(ICMMCCE 2015), Xian, China, 2015, PP.2805-2808.

[14] S.Y Zheng, et al, Design and Implementation of Supermarket Personnel Management System 
Based On Java, in: PROCEEDINGS OF THE 2015 INTERNATIONAL CONFERENCE ON EDUCATION,MANAGEMENT AND COMPUTING TECHNOLOGY, Tianjin, China, 2015, PP.1724-1727.

[15] S.Y Zheng, et al, Analysis of Internet of Things Talent Training and Curriculum System Innovation, in: PROCEEDINGS OF THE 2016 INTERNATIONAL CONFERENCE ON EDUCATION,MANAGEMENT AND COMPUTING TECHNOLOGY(ICEMCT-16), Hangzhou, China, 2016, PP.957-960.

[16] S.Y Zheng, et al, Brief analysis on“HeYuanTong"Campus Mobile Phone APP Design, in: PROCEEDINGS OF THE 2015 5TH INTERNATIONAL CONFERENCE ON COMPUTER SCIENCES AND AUTOMATION ENGINEERING, Sanya, China, 2015, PP.151-154. 